\title{
Patient comfort scores do not affect endoscopist behavior during colonoscopy, while trainee involvement has negative effects on patient comfort
}

\section{다(1) $(9)$}

\author{
Authors \\ Brian P.H. Chan ${ }^{1}$, Amanda Hussey ${ }^{1}$, Natalie Rubinger ${ }^{1}$, Lawrence C. Hookey ${ }^{2}$
}

Institutions

1 Queen's University, Department of Medicine, Kingston Ontario, Canada

2 Queen's University, Gastrointestinal Diseases Research Unit, GI Division Hotel Dieu Hospital, Kingston Ontario, Canada

submitted 7.8.2016

accepted after revision 2.5.2017

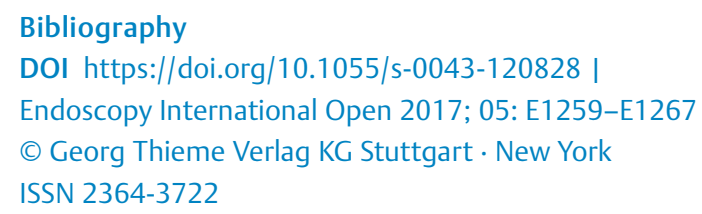

\section{Corresponding author}

Dr. Lawrence C. Hookey, Associate Professor, Queen's University, Division of Gastroenterology, Hotel Dieu Hospital, 166 Brock Street, Kingston Ontario, Canada K7L $5 G 2$

Fax: +613-548-2426

hookeyl@hdh.kari.net

\begin{abstract}
Introduction Patient comfort is an important part of endoscopy and reflects procedure quality and endoscopist technique. Using the validated, Nurse Assisted Patient Comfort Score (NAPCOMS), this study aimed to determine whether the introduction of NAPCOMS would affect sedation use by endoscopists.
\end{abstract}

Patients and methods The study was conducted over 3 phases. Phase One and Two consisted of 8 weeks of endoscopist blinded and aware data collection, respectively. Data in Phase Three was collected over a 5-month period and scores fed back to individual endoscopists on a monthly basis.

Results NAPCOMS consists of 3 domains - pain, sedation, and global tolerability. Comparison of Phase One and Two, showed no significant differences in sedative use or NAPCOMS. Phase Three data showed a decline in fentanyl use between individual months $(P=0.035)$, but no change in overall NAPCOMS. Procedures involving trainees were found to use more midazolam $(P=0.01)$ and fentanyl $(P=$ $0.01)$, have worse NAPCOMS scores, and resulted in longer procedure duration $(P<0.001)$. Data comparing gastroenterologists and general surgeons showed increased fentanyl use $(P=0.037)$, decreased midazolam use $(P=0.001)$, and more position changes $(P=0.002)$ among gastroenterologists.

Conclusions The introduction of a patient comfort scoring system resulted in a decrease in fentanyl use, although with minimal clinical significance. Additional studies are required to determine the role of patient comfort scores in quality control in endoscopy. Procedures completed with trainees used more sedation, were longer, and had worse NAPCOMS scores, the implications of which, for teaching hospitals and training programs, will need to be further considered.

\section{Introduction}

Colonoscopy is used for evaluation, diagnosis and treatment of gastroenterological disorders. Colon cancer is the third most commonly diagnosed cancer in North America [1,2]. Fecal occult blood testing and colonoscopy remain 2 of the most widely used screening tools for colorectal cancer $[3,4]$.
There can be considerable variation in the quality of endoscopy and quality assurance in this field continues to gain importance in the eyes of administrators, endoscopists, and patients [5]. The American Society for Gastrointestinal Endoscopy identified 3 priority quality indicators for colonoscopy: adenoma detection rate (ADR), cecal intubation rate (CIR), and adherence to surveillance protocols [6]. A higher CIR is associated with increases in ADR [7] but a focus on CIR may result in 
endoscopists using more force to advance the instrument, with concomitant increased sedation requirements. An unintended consequence of this may be an increase in complications such as perforation. Numerous societies have proposed sedation as a quality indicator during colonoscopy, while the Canadian Association of Gastroenterology and British Society for Gastroenterology have included patient comfort as an additional performance indicator [6, 8-10].

Sedation practices vary widely between centers, regions, and endoscopists. In Ontario, Canada, over $90 \%$ of colonoscopies are completed with sedation and among these the most common practice is to use a combination of a benzodiazepine and narcotic agent [11]. This is consistent throughout Canada. Similarly, in the United States and Australia, greater than $90 \%$ of colonoscopies use intravenous sedation [12]. In Canada, deep sedation with propofol is estimated at $13 \%$, with a higher proportion in Ontario at $23 \%$ [11]. Sedation use is highly variable in European nations. In Norwegian centers, mean sedation rate was $25 \%$, Portugal $-24.5 \%$, and UK-94.6\% [12]. Agents used for sedation differ from country to country.

There exist a variety of well-validated patient comfort scales ranging from generic to colonoscopy specific [13-18]. The Colorado Numerical Pain Scale [16] was developed in 2002 and consists of a $0-5$ nurse assessed pain scale, with high interrater reliability. It is a global rating, which is simple and easy to use, but fails to record frequency and duration of pain. Vargo et. al. developed a Patient/Clinician Satisfaction with Sedation Instrument (PSSI, CSSI), with good correlation between PSSI and CSSI scores [18]. However, it is a 16-item score, making it difficult to implement in routine clinical use. The La Cross (WI) Intra-Endoscopy Sedation Comfort Score (L-WISC) [17], is a 4point scale examining comfort in sedation. It showed good inter-rater reliability between physicians and nurses, but poor correlation with patient scores. It is a global rating and does not describe intensity of pain, or differentiate between frequency and duration of pain. The Nurse-Assessed Patient Comfort Score (NAPCOMS) was validated in the United Kingdom and Canada and developed in centers using minimal to moderate sedation, making it the most representative tool for our patient population [15]. During development of NAPCOMS, there was good correlation between NAPCOMS and endoscopist ratings, as well as NAPCOMS and patient ratings (both immediately post procedure and one week later), facilitating a one-time measurement. It records intensity, frequency, and duration of pain, while also measuring level of sedation and perceived global comfort.

The Hawthorne effect is a phenomenon that the very monitoring of people's behavior affects that behavior. It was originally described in 1933, when employees at the Western Electric telephone manufacturing company were found to have higher productivity when intensely supervised. It has since been formally recognized in the field of behavioral sciences and can be found throughout research. The Hawthorne effect has primarily been investigated in quality control and endoscopy, in particular with respect to polyp and adenoma detection rates [19-23].
The aim of this study was to determine whether the introduction of a patient comfort score would affect the amount of sedation administered in patients undergoing routine outpatient colonoscopy.

\section{Patients and methods}

The study consisted of 3 phases. In Phase One (P1), NAPCOMS was introduced to the endoscopy unit without informing endoscopists. In Phase Two (P2), endoscopists were informed that patient comfort was being monitored and recorded. Data from P1 and P2 were compared to see if there were any differences. The objective of Phase Three (P3) of the study was to make the Hawthorne effect more pronounced by informing endoscopists of group and individual performance data on a monthly basis.

\section{Population}

All patients undergoing outpatient colonoscopy at Hotel Dieu Hospital, in Kingston, Ontario were included in the study from a period of January 2014 to April 2014, and from January 2015 to June 2015. The Hotel Dieu Hospital Endoscopy Unit is an ambulatory endoscopy unit staffed by dedicated endoscopy nurses. The colonoscopy patient population is varied and indications include screening, surveillance, symptom assessment and therapeutics (stricture dilation, large polyp endoscopic mucosal resection). Conscious sedation is practiced at our center, with the standard of care being intravenous midazolam and fentanyl, administered by nurses under the guidance of the endoscopist.

The modified NAPCOMS was introduced to the endoscopy unit staff in November 2013, with 2 seminars prior to live use to ensure adequate nursing training in assessment and data collection. Twelve endoscopists were involved in the study (11 in $\mathrm{P} 1$ and $\mathrm{P} 2$, and 12 in $\mathrm{P} 3$ ), consisting of 8 gastroenterologists and 4 general surgeons. Apart from the addition of an additional endoscopist in P3, there were no changes in endoscopists. All endoscopists were experienced (more than 100 colonoscopies per year) and most complete greater than 200 colonoscopies per year. Eight gastroenterologists and 2 general surgeons have taken the Canadian Association of Gastroenterology Skills Enhancement in Endoscopy Train the Colonoscopy Trainer course, which aims to teach endoscopists how to effectively supervise and instruct trainees. One of the objectives of this course is addressing variations in technique for insertion of the colonoscope, with aims of both increasing success and patient comfort during the procedure.

\section{Design}

Phase One and Two of the study ran for a 16-week period from January to April 2014. Phase One was blinded to the endoscopist; they were unaware they were being monitored. This was achieved by integrating NAPCOMS into routine nursing forms. In Phase Two, endoscopists were informed verbally and via email by the Medical Director of Endoscopy that patient comfort was being assessed and data collected for an additional 8 weeks. At the time of disclosure, the score and it's compo- 
nents were explained to endoscopists. In Phase Three, group means and ranges were included with individual scores to potentiate the Hawthorne effect. No additional instructions were provided otherwise.

Phase Three was conducted from January 2015 to June 2015. Sedative use, NAPCOMS results, as well as adjunctive data such as patient position changes and use of abdominal pressure was collected on a monthly basis and summarized. Physicians received, via email, monthly performance reports that included personal results as well as monthly group data (mean score, sedation used, and position changes).

\section{Sample size}

A sample size of 50 is recommended as a minimum requirement for testing associations or drawing inferences [24], especially in a study such as this which was used to gather new baseline data. Sample size calculations to assess changes in fentanyl doses suggested $35-200$ patients be included in each group to allow for detection of difference of $20-30 \%$, a figure we concluded would be clinically relevant. Based on the results from P1 and P2, which showed little variation between groups in sedation and NAPCOMS, a calculated sample size of greater than 10,000 cases would have been required to achieve statistical significance in NAPCOMS scores in P3. However, we elected to proceed with P3 over 6 months to assess whether direct reporting of results to endoscopists would bring about the changes we had expected between P1 and P2.

\section{Outcomes}

The primary outcome was a change in the total amount of sedation used; between P1 and P2, and in P3, over the duration of the study. Secondary outcomes were a change in NAPCOMS or adjunctive measures (position changes, abdominal pressure), over the same time periods described. A change in NAPCOMS could either be for each individual component (pain, sedation, global tolerability), or a composite pain score. Position changes were recorded as binary and as a mean, while abdominal pressure was only a binary measurement. During the study, we also looked at differences among groups, including general surgery and involvement of trainees.

The Nurse-Assessed Patient Comfort Score (NAPCOMS) was adopted to determine patient comfort during colonoscopy. NAPCOMS is a composite pain score that includes intensity, frequency, and duration, on a scale of 0 to3, with 3 being worse
[15]. Sedation and global tolerability are treated separately, on a 0 to 3 scale. A NAPCOMS score of six or greater correlates with a patient rating of moderate to severe discomfort. The NAPCOMS score sheet was modified to collect additional data, including trainees, type of colonoscope used, patient demographics, complications, sedative use, procedure duration, and adjunctive measures such as position changes and abdominal pressure ( Appendix $\mathbf{1}$ ).

\section{Statistics}

Data were imported into SPSS (version 22, IBM, Armonk, NY, USA). Demographic characteristics of the patient population were described using means and standard deviations for continuous data, and frequencies and percentages for categorical data. Continuous data were also plotted to assess the normality of the underlying distributions. Most were acceptable, but sedative administration was mildly skewed so non-parametric tests were used to confirm the findings of the parametric tests. Repeated measures ANOVA was used to assess patterns over time, with the endoscopist added in as a factor to identify any between-endoscopist effects. Differences in sedative administration prior to and after introduction of NAPCOMS were assessed using the student's t-test, and confirmed using the MannWhitney U.

Ethics approval was obtained and renewed from the Health Sciences Research Ethics Board from Queen's University.

\section{Results}

One hundred and ninety-five procedures were documented in P1, and 201 in P2. Of these, 343 were completed by GI, and 53 by GS. Baseline characteristics between the groups were similar ( $\triangleright$ Table 1). In P3, 932 cases were documented; GI-773, and GS-159.

Phase One and Two were designed to test whether the introduction of a patient comfort scoring system would affect endoscopist behavior on sedative administration. Midazolam, fentanyl and hyoscine butylbromide were the only sedative agents used and there were no statistically significant differences in the amount of sedative use between P1 and P2, our primary endpoint. There were no statistically significant differences in NAPCOMS. Average overall NAPCOMS score was 3.07. Global tolerability $(P=0.052)$ showed increased comfort in $\mathrm{P} 2$, but did not reach statistical significance. There was a higher

- Table 1 Phase One and Two baseline characteristics.

\begin{tabular}{|c|c|c|c|c|}
\hline Parameter & $\begin{array}{l}\text { Total } \\
(n=396)\end{array}$ & $\begin{array}{l}\text { Phase One } \\
(n=195)\end{array}$ & $\begin{array}{l}\text { Phase Two } \\
(n=201)\end{array}$ & $P$ \\
\hline Male & $186(47.8 \%)$ & $97(50.5 \%)$ & $89(45.2 \%)$ & 0.29 \\
\hline No trainee & $288(77.6 \%)$ & $140(74.9 \%)$ & $148(80.4 \%)$ & 0.20 \\
\hline Adult scope & $324(89.8 \%)$ & $163(91.6 \%)$ & $161(88.0 \%)$ & 0.49 \\
\hline Previous Colonoscopy & $235(62 \%)$ & $111(60.7 \%)$ & $124(63.3 \%)$ & 0.60 \\
\hline Previous Surgery & $124(36.3 \%)$ & $53(32.7 \%)$ & $71(39.4 \%)$ & 0.20 \\
\hline
\end{tabular}




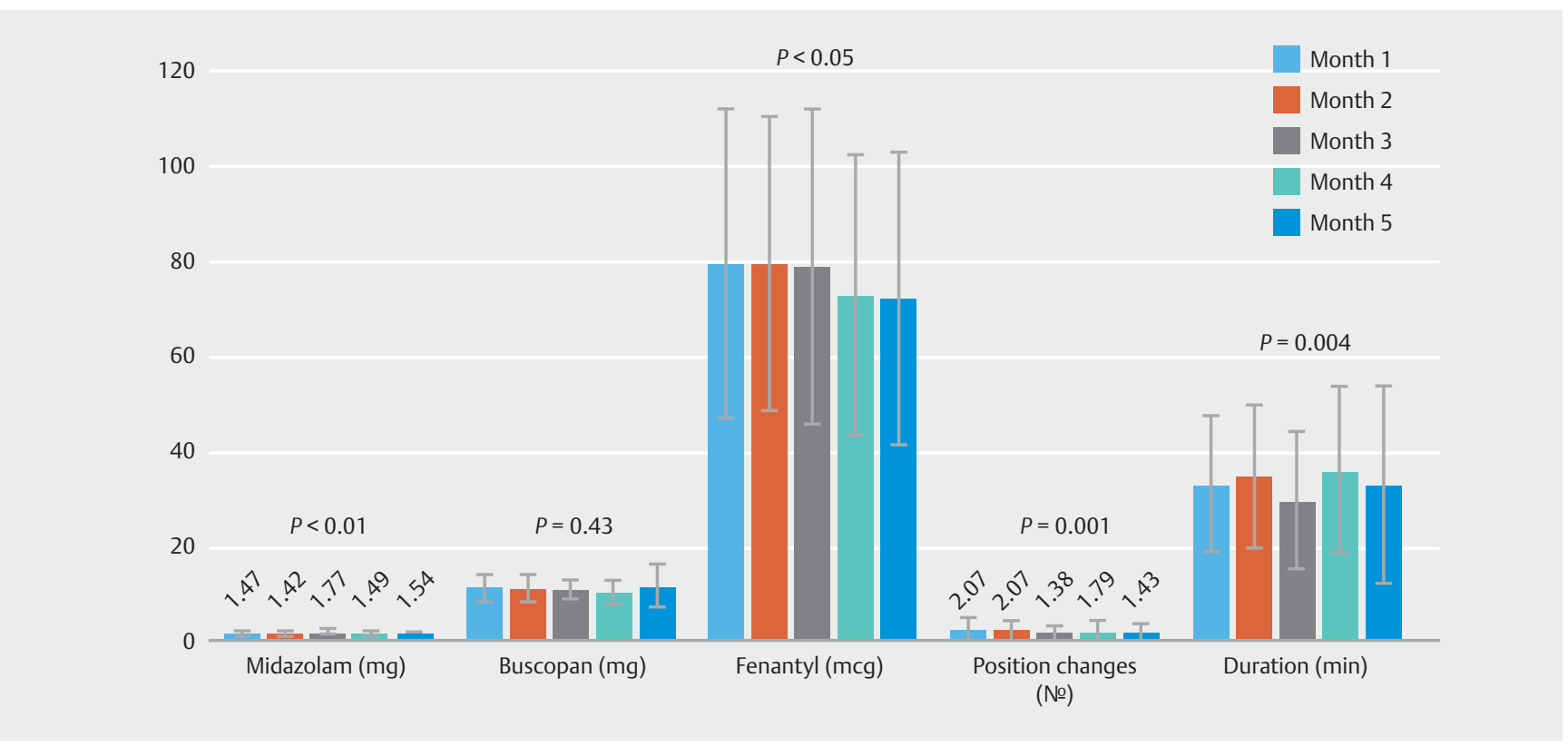

- Fig. 1 Phase Three procedural documentation - sedative use, number of position changes, and procedure duration.

proportion of cases where position changes were used in P2 (blinded $n=103$, open $n=163, P=0.003$ ), however, the mean number of position changes did not reach statistical significance by group (blinded $3.01 \pm 1.84$, open 3.41 $\pm 2.25, P=$ $0.19)$. There was a statistically significant increase in the use of hyoscine butylbromide in P2, however this is accounted for entirely by 1 physician.

Phase Three collected and reported results to endoscopists on a monthly basis. Data was analyzed across months, by endoscopist, and comparing the first month to all other months in the study. Endoscopist data showed many differences, reflecting different physician preferences and are not reported here. There were no discernable patterns in the data. Comparison of monthly data showed a decrease in fentanyl use as the study progressed $(P=0.035,75.57 \mathrm{mcg}, 95 \% \mathrm{Cl} 73.50,77.64)$, and variation in midazolam use $(P<0.001)$, number of position changes $(P=0.001)$, and procedure duration $(P=0.004)$ but no trend towards increased or decreased amount ( $\triangleright$ Fig. 1$)$. This correlated with heterogeneous results between months in NAPCOMS global tolerability score. Composite NAPCOMS, sedation score, and use of abdominal pressure showed no statistically significant differences. Average NAPCOMS score was 2.97.

In all phases, we compared results between gastroenterologists and general surgeons. Combining all data in P1 and P2, general surgeons used higher amounts of midazolam (gastroenterologists $1.45 \pm 0.56 \mathrm{mg}$, general surgeons $2.08 \pm 0.67 \mathrm{mg}$; $P=0.001$ ), although there were no differences in NAPCOMS. Gastroenterologists had a higher proportion of position changes $(P<0.001)$ but the mean number showed no differences. In P3, we once again saw increased amounts of midazolam use (gastroenterologists $1.51 \pm 0.85 \mathrm{mg}$, general surgeons $1.69 \pm$ $0.57 \mathrm{mg} ; P=0.001)$ and fewer position changes both in proportion $(P=0.002)$ and mean $(P=0.01)$ used by general surgeons. Gastroenterologists used higher amounts of fentanyl (gastro- enterologists $76.52 \pm 30.92 \mathrm{mcg}$, general surgeons $70.50 \pm$ 32.59 mcg; $P=0.037$ ), a result which was not observed in $P 1 /$ P2 (gastroenterologists $87.21 \pm 37.38 \mathrm{mcg}$, general surgeons $88.73 \pm 40.41 \mathrm{mcg} ; P=0.79$ ). There remained no statistically significant differences in NAPCOMS. There was no difference in procedure duration in any phase ( $\bullet$ Fig. 2 ).

Using combined P1 and P2 data, we compared colonoscopies performed by trainees versus no trainee. Baseline characteristics were similar between groups. Trainees used significantly more midazolam (no trainee $1.52 \pm 0.57 \mathrm{mg}$, trainee $1.69 \pm 0.72 \mathrm{mg} ; P=0.02$ ) and fentanyl (no trainee $85.47 \pm$ $29.20 \mathrm{mg}$, trainee $96.61 \pm 56.50 \mathrm{mg} ; P=0.01)$, while their procedures were longer (no trainee $30.75 \pm 12.59$ minutes, trainee $43.92 \pm 15.51$ minutes; $P<0.001$ ), and NAPCOMS scores worse in all domains except level of sedation ( $\triangleright$ Fig.3).

\section{Discussion}

The aim of this study was to determine if the introduction of a patient comfort scoring system would affect physician behavior in regard to sedative use. Phase One and Two assessed endoscopist-blinded and-aware behavioral response, and Phase Three the effect of monthly feedback. Conventionally, quality control measures in colonoscopy have included CIR, ADR, and adherence to guidelines. Patient comfort plays an important role in patient satisfaction and is also a measure of endoscopic quality and technique [25]. Healthcare delivery is increasingly patient focused and patient comfort scores such as NAPCOMS help us quantify the patient experience.

In the first 2 phases of our study, there was no difference in sedative administration or NAPCOMS scores between pre- and post-intervention periods. A potential explanation was that monitoring was unobtrusive and not recognized by the endoscopist. Endoscopists were only informed one time that they 


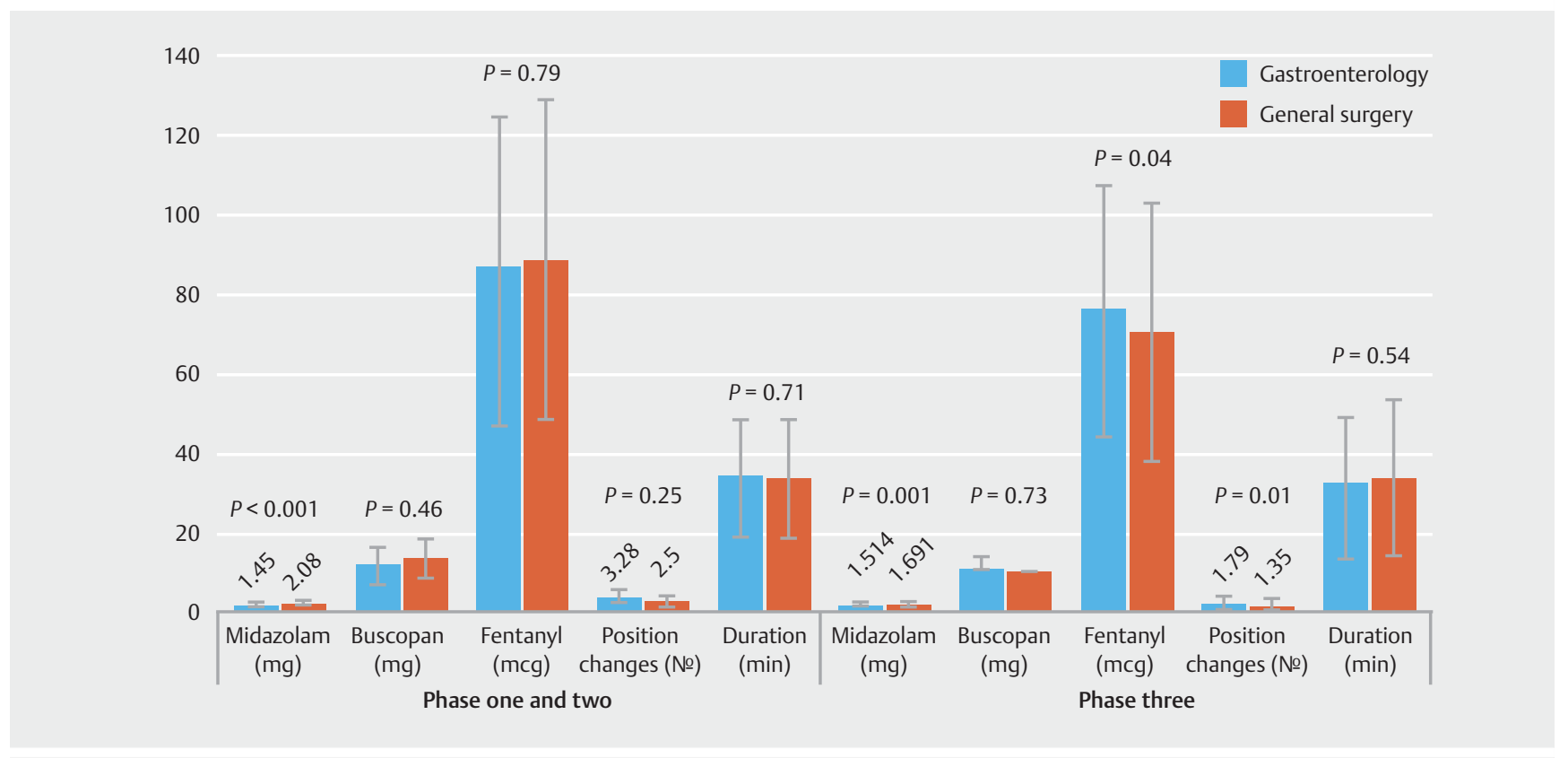

Fig. 2 Gastroenterology compared to general surgery procedural documentation - sedative use, number of position changes, and procedure duration.

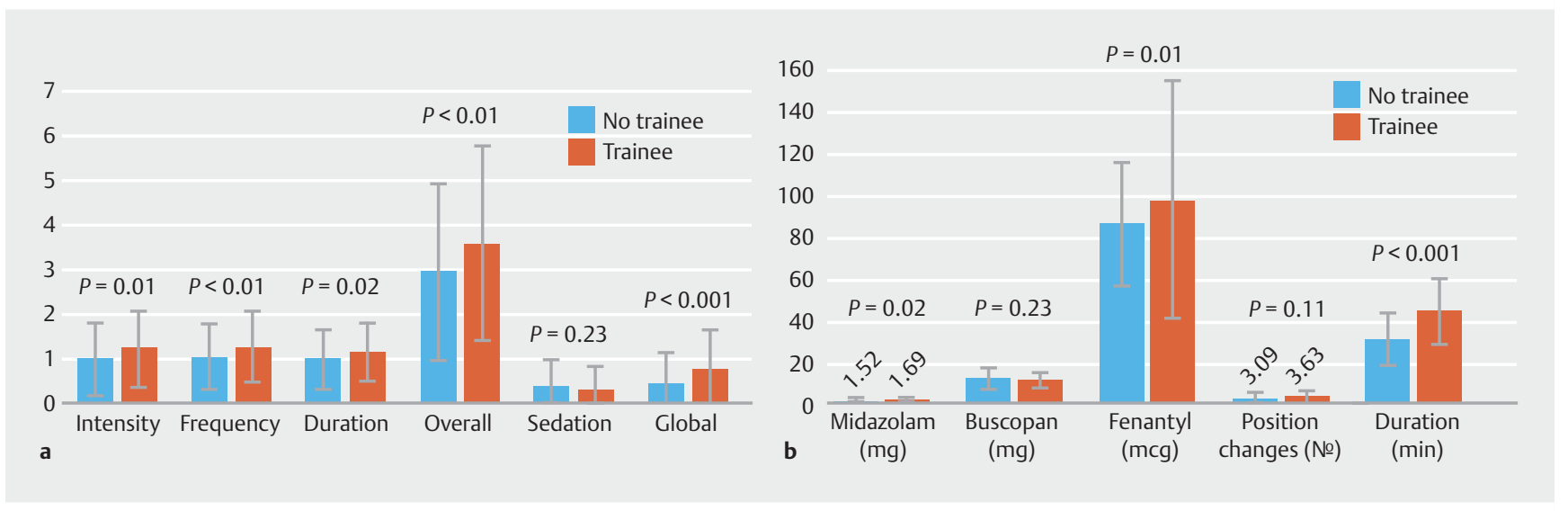

- Fig. 3 Comparison of no trainee and trainee procedures. a NAPCOMS. b Sedative use, position changes, and procedure duration.

were being monitored in the endoscopist aware period, and thus may have quickly forgotten. To test this theory, P3 fed back each endoscopists individual data on a monthly basis plus group means and ranges. There was a statistically significant decrease in fentanyl use and duration of pain. While statistically significant, the clinical significance was minimal, as evidenced by no overall change in NAPCOMS. Direct comparison among individual endoscopists was not provided as feedback. Doing so may have produced a more significant Hawthorne effect.

We expected to see an increase in medication use and correspondingly, a decrease in NAPCOMS. This did not occur in any comparison. We would have required greater than 10,000 exams to look for miniscule differences in NAPCOMS. NAPCOMS is a composite of intensity, frequency, and duration of pain for a total score of nine. Level of sedation and global tolerability were assessed separately in the original paper. In P1 and P2, average overall NAPCOMS was 3.07 and in P3, 2.97. This is lower than the average reported in the original paper (3.2) [15]. Results from the use of NAPCOMS have not been widely published, and therefore, we are unaware of a normal range. If our scores are low compared to this range, this would affect our results.

Comfort scores have been correlated with performance. In 2010, comfort scores using nurse-reported comfort levels were compared to CIR and polyp detection rate [26]. Endoscopists with higher patient comfort scores were found to have higher polyp removal and CIR. Improved comfort scores were associated with less sedative use. In contrast, work presented in abstract form showed "standard" doses of midazolam resulted in higher CIR and polyp detection rate compared to doses less than $2 \mathrm{mg}[27,28]$. Notably, standard doses in the abstract 
were $2 \mathrm{mg}$, which is higher than the average doses seen at our center.

\section{Physician specialty}

Practice differences between general surgery and gastroenterology were compared in our study. We consistently found general surgeons used fewer position changes and in P3, less fentanyl and more midazolam. While statistically significant, clinically, there was no effect on NAPCOMS.

There remains debate in the literature among the quality of endoscopy among different stakeholders. A study comparing practice habits between nurses, GS, and GI fellows found no differences in effectiveness or patient satisfaction in flexible sigmoidoscopy [29]. A study by Mehran et. al. comparing general surgeons, colorectal surgeons, and gastroenterologists showed no difference in complication rates, and shorter procedure time among GS [30]. On the contrary, a cross sectional study of endoscopists from seven Montreal (gastroenterologists 36, general surgeons $6, n=2113$ ) and 2 Calgary (gastroenterologists 31 , general surgeons $5, n=538$ ) endoscopy centers found in the Montreal center, general surgeons were half as likely to remove polyps compared to gastroenterologists [31]. Adjusted odds ratio for general surgeons compared to gastroenterologists was 0.48 (95\% Cl: $0.32-0.71)$ and $0.73(95 \% \mathrm{Cl}: 0.43-$ 1.21) for Montreal and Calgary, respectively. Our study showed differences in practice habits between gastroenterology and general surgery, but no difference in overall quality.

\section{Position changes}

Position changes are used in colonoscopy to improve luminal distention, allowing for better visualization. Several studies have demonstrated the benefit of position changes on ADR, which reflects quality of colonoscopy. East et. al. showed that position changes improved luminal distention during withdrawal but did not assess ADRs [32]. Three randomized trials compared colonoscopy performed in left lateral decubitus to dynamic position changes on ADR and found a $9.8 \%$ [33], $18 \%$ [34], and 9.4\% [35] absolute increase in ADR in the group with position changes. Position changes can also be used to facilitate insertion of the colonoscope, resulting in better tolerance. There was no difference in position changes in any phase. Position changes were used more frequently by $\mathrm{Gl}$ in our study but resulted in no clinical differences.

\section{Trainees and endoscopy}

Most major gastroenterology societies have released guidelines on principles of endoscopy training and minimal competency procedural thresholds. Despite this, there have been few guidelines specific to how endoscopists should be trained. Similarly, there have been limited studies examining patient comfort in endoscopy when comparing trainee procedures to attending staff alone. Our study showed that trainees used more sedation, had longer procedures, and resulted in more patient discomfort compared to staff alone. Our group has previously reported extension of procedure time by $50 \%$ in ambulatory colonoscopy when trainees are involved [36].
Data comparing patient comfort in trainees to staff procedures are conflicting and arise mainly from validation of training techniques and quality assurance studies. Flexible sigmoidoscopy completed by senior internal medicine residents was compared to staff, and while procedures involving residents were longer, satisfaction and comfort did not differ between groups [37]. Additional studies in colonoscopy have shown that trainee involvement have no effect on satisfaction, pain, or comfort [38, 39]. In 1 study, trainee procedures were longer, used more sedation, and had lower CIR rates [39]. In contrast, a comparison of patient satisfaction among gastroenterologists, internists, and nurse practitioners found procedures involving trainees had less overall satisfaction, and more pain and discomfort [40]. A comparison of residents randomized to simulation or patient based training found both groups had higher discomfort scores compared to staff [41]. All of these studies used patient based questionnaires to determine comfort, while ours was nurse assessed. Ultimately, data from trainees to attending staff procedures remain conflicting, with our study suggesting trainee involvement may lead to more sedative use and patient discomfort. The implications of this for teaching hospitals and training programs will need to be further considered.

Trainee effects on other measures of quality have been studied to some degree. Work presented in abstract form showed that trainees had longer withdrawal time compared to staff alone [42]. This is consistent with our findings and is intuitive, given lower technical proficiency and the addition of teaching during trainee endoscopy. Several groups have looked at ADR and again, results are conflicting. Shah et. al. and Eckardt et. al. did not find any difference in ADR between staff and trainees $[43,44]$. In Eckardt, there was a trend towards increased ADR in the staff group but this was not significant $(19.3 \%$ vs $14.9 \%, P=$ 0.27). Other studies have shown improved adenoma detection with trainee involvement [45-47], with the prevailing theory that two sets of eyes are better than one. Notably, in the study by Peters et. al., level of training was associated with a higher polyp detection rate and ADR, with third-year fellows having significantly better performance compared to their junior colleagues. Although withdrawal time increases ADR, these results show that experience also plays a large factor.

It is widely accepted that trainees increase procedure time in endoscopy. Studies to date are conflicting in regard to trainee effects on endoscopy quality and patient comfort. While our study showed trainees used more sedation and had worse comfort scores, we cannot directly relate this to quality. Additional studies would be required to correlate our findings with established colonoscopy quality indices.

\section{Limitations}

Our study focused mainly on sedative use and perceived patient comfort during procedures. We did not measure established markers of quality in endoscopy and doing so would help correlate our findings with previous studies. As this was a single center study, there was a relatively low volume of colonoscopies included. This was particularly amplified in the general surgery analysis, which had a minimal case volume compared to gastro- 
enterology. The small general surgery case volume may affect the comparisons presented in this paper.

\section{Conclusion}

Introduction of a patient comfort scoring system resulted in a statistically significant decrease in fentanyl use, although with minimal clinical significance, as there was no change in NAPCOMS. Additional studies are required to determine the role of patient comfort scores in quality control in endoscopy. Procedures completed with trainees used more sedation, were longer, and had worse NAPCOMS scores, the implications of which, for teaching hospitals and training programs, will need to be further considered.

\section{Acknowledgements}

The authors would like to acknowledge Wilma Hopman, whose statistical expertise was invaluable throughout the project and manuscript development.

\section{Competing interests}

None

\section{References}

[1] Canadian Cancer Society. Colorectal cancer statistics. Canadian Cancer Society [Internet]; 2015: [cited 2016 Jan 17]. Available from: http://www.cancer.ca/en/cancer-information/cancer-type/colorectal/statistics/?region=on

[2] American Cancer Society. Key statistics for colorectal cancer [Internet]. American Cancer Society.; 2015: [cited 2016 Jan 17]. Available from: http://www.cancer.org/cancer/colonandrectumcancer/detailedguide/colorectal-cancer-key-statistics

[3] Levin B, Lieberman DA, McFarland B et al. Screening and surveillance for the early detection of colorectal cancer and adenomatous polyps, 2008: a joint guideline from the American Cancer Society, the US Multi-Society Task Force on Colorectal Cancer, and the American College of Radiology. CA Cancer J Clin 2008; 58: 130-160

[4] Rex DK, Johnson DA, Anderson JC et al. Colorectal cancer screening. Am J Gastroenterol 2009; 104: 739-750

[5] Tinmouth J, Kennedy E, Baron D et al. A Quality Initiative of the Program in Evidence-Based Care ( PEBC ), Cancer Care Ontario ( CCO ) Guideline for Colonoscopy Quality Assurance in Ontario A Quality Initiative of the Program in Evidence-Based Care ( PEBC ), Cancer Care Ontario ( CCO ) Guidel. Cancer Care Ontario, Progr Evidence-based Care Evidence-based Ser 2013; 15: 1 - 820

[6] ASGE. Quality indicators for colonoscopy. Gastrointest Endosc 2015; 101: $873-885$

[7] Lee TJW, Rutter MD, Blanks RG et al. Colonoscopy quality measures: experience from the NHS Bowel Cancer Screening Programme. Gut 2012; 61: $1050-1057$

[8] Rizk MK, Sawhney MS, Cohen J et al. Quality indicators common to all $\mathrm{Gl}$ endoscopic procedures. Gastrointest Endosc 2015; 81: 3-16

[9] Rees C], Gibson ST, Rutter MD et al. UK Key Performance Indicators \& Quality Assurance Standards for Colonoscopy [Internet]. British Society of Gastroenterology; 2013: [cited 2016 Jan 17]. Available from: http://www.bsg.org.uk/images/stories/docs/clinical/guidance/uk_kpi_qa_standards_for_colonoscopy.pdf

[10] Armstrong D, Barkun AN, Bridges R et al. Canadian Association of Gastroenterology consensus guidelines on safety and quality indicators in endoscopy. Can J Gastroenterol 2012; 26: 17 - 31

[11] Porostocky P, Chiba N, Colacino P et al. A survey of sedation practices for colonoscopy in Canada. Can J Gastroenterol 2011; 25: 255-260

[12] Ladas SD, Satake Y, Mostafa I et al. Sedation practices for gastrointestinal endoscopy in Europe, North America, Asia, Africa and Australia. Digestion 2010; 82: $74-76$

[13] Sanchez del Rio A, Baudet JS, Fernadez O et al. Evaluation of patient satisfaction in gastrointestinal endoscopy. Eur J Gastroenterol Hepatol 2007; 19: 896-900

[14] de Jonge V, Sint Nicolaas], Lalor EA et al. A prospective audit of patient experiences in colonoscopy using the Global Rating Scale: a cohort of 1,187 patients. Can J Gastroenterol 2010; 24: 607-613

[15] Rostom A, Ross ED, Dubé C et al. Development and validation of a nurse-assessed patient comfort score for colonoscopy. Gastrointest Endosc 2013; 77: 255-261

[16] Salmore R. Development of a new pain scale: Colorado Behavioral Numerical Pain Scale for sedated adult patients undergoing gastrointestinal procedures. Gastroenterol Nurs 2002; 25: 257-262

[17] Munson GW, Van Norstrand MD, O'donnell J] et al. Intraprocedural evaluation of comfort for sedated outpatient upper endoscopy and colonoscopy: the La Crosse (WI) intra-endoscopy sedation comfort score. Gastroenterol Nurs 2011; 34: 296-301

[18] Vargo J, Howard K, Petrillo J et al. Development and validation of the patient and clinician sedation satisfaction index for colonoscopy and upper endoscopy. Clin Gastroenterol Hepatol 2009; 7: 156 - 162

[19] Keswani RN, Yadlapati R, Gleason KM et al. Physician Report Cards and Implementing Standards of Practice Are Both Significantly Associated With Improved Screening Colonoscopy Quality. Am J Gastroenterol 2015; 110: $1134-1139$

[20] Ussui V, Coe S, Rizk C et al. Stability of Increased Adenoma Detection at Colonoscopy. Follow-Up of an Endoscopic Quality Improvement Program-EQUIP-II. Am J Gastroenterol 2014; 110: 1 -8

[21] Coe SG, Crook JE, DiehI NN et al. An endoscopic quality improvement program improves detection of colorectal adenomas. Am J Gastroenterol 2013; 108: 219-226

[22] Sanaka MR, Super DM, Feldman ES et al. Improving compliance with postpolypectomy surveillance guidelines: an interventional study using a continuous quality improvement initiative. Gastrointest Endosc 2006; 63: 97-103

[23] Rex DK, Hewett DG, Raghavendra M et al. The impact of videorecording on the quality of colonoscopy performance: a pilot study. Am J Gastroenterol 2010; 105: 2312-2317

[24] Altman D. Practical Statistics for Medical Research. Chapman and Hall/CRC; 1990: 624

[25] Ekkelenkamp VE, Dowler K, Valori RM et al. Patient comfort and quality in colonoscopy. World J Gastroenterol 2013; 19: 2355-2361

[26] Ekkelenkamp VE, Shaw I, Valori R et al. Comfort scores in colonoscopy performance. Gut 2011; 60: (Suppl. 01): A44-45

[27] Boyd J, Lee L, Lanzon-Miller S. BSG 2014 abstracts BSG 2014 abstracts OC-040. Gut 2014; 25: (Suppl. 01): $2014-6$

[28] Boyd J, Harper C, Chapman T et al. BSG 2014 abstracts. Gut 2014; 63 (Suppl. 01): 2014

[29] Schoenfeld PS, Cash B, Kita J et al. Effectiveness and patient satisfaction with screening flexible sigmoidoscopy performed by registered nurses. Gastrointest Endosc 1999; 49: 158-162

[30] Mehran A, Jaffe P, Efron J et al. Colonoscopy: why are general surgeons being excluded? Surg Endosc 2003; 17: 1971-1973 
[31] Jiang M, Sewitch M], Barkun AN et al. Endoscopist specialty is associated with colonoscopy quality. BMC Gastroenterol 2013; 13: 78

[32] East JE, Suzuki N, Arebi N et al. Position changes improve visibility during colonoscope withdrawal: a randomized, blinded, crossover trial. Gastrointest Endosc 2007; 65: 263-269

[33] Koksal AS, Kalkan IH, Torun S et al. A simple method to improve adenoma detection rate during colonoscopy: altering patient position. Can J Gastroenterol 2013; 27: 509-512

[34] East JE, Bassett P, Arebi N et al. Dynamic patient position changes during colonoscope withdrawal increase adenoma detection: a randomized, crossover trial. Gastrointest Endosc 2011; 73: 456-463

[35] Lee S-W, Chang JH, Ji J-S et al. Effect of Dynamic Position Changes on Adenoma Detection During Colonoscope Withdrawal: A Randomized Controlled Multicenter Trial. Am J Gastroenterol 2016; 111: 63-69

[36] Depew WT, Hookey LC, Vanner SJ et al. Opportunity costs of gastrointestinal endoscopic training in Canada. Can J Gastroenterol 2010; 24: $733-738$

[37] Jackson JL, Osgard E, Fincher RK. Resident participation in flexible sigmoidoscopy does not affect patient satisfaction. Am J Gastroenterol 2000; 95: $1563-1566$

[38] Eckardt A], Swales C, Bhattacharya K et al. Open access colonoscopy in the training setting: which factors affect patient satisfaction and pain? Endoscopy 2008; 40: $98-105$

[39] Sarkar S, Athwal V, Sturgess RP et al. The effect of high quality assurance measures in bowel cancer screening on patient satisfaction of colonoscopy. J Gastrointestin Liver Dis 2012; 21: 251-258
[40] Schoen RE, Weissfeld JL, Bowen N] et al. Patient Satisfaction With Screening Flexible Sigmoidoscopy. Arch Intern Med 2000; 160: 1790

[41] Sedlack RE, Kolars JC, Alexander JA. Computer simulation training enhances patient comfort during endoscopy. Clin Gastroenterol Hepatol 2004; 2: 348-352

[42] de Groen PC, Srinivasan N, Stanek S et al. 73 Automated, Objective Measurements of Colonoscopy Technique: A Comparison Between Trainees and Staff. Gastroenterology 2013; 144: 15-16

[43] Shah N, Sanaka MR, Mullen KD et al. Comparison of Polyp Detection Rates During Colonoscopy by Attending Staff Alone Versus Trainee Plus Attending Staff: Are Two People Better Than One? Gastrointest Endosc 2005; 61: AB264

[44] Eckardt A], Swales C, Bhattacharya K et al. Does trainee participation during colonoscopy affect adenoma detection rates? Dis Colon Rectum 2009; 52: 1337 - 1344

[45] Peters SL, Hasan AG, Jacobson NB et al. Level of fellowship training increases adenoma detection rates. Clin Gastroenterol Hepatol 2010; 8: $439-442$

[46] Buchner AM, Shahid MW, Heckman MG et al. Trainee participation is associated with increased small adenoma detection. Gastrointest Endosc 2011; 73: $1223-31$

[47] Rogart JN, Siddiqui UD, Jamidar PA et al. Fellow involvement may increase adenoma detection rates during colonoscopy. Am J Gastroenterol 2008; 103: $2841-2846$ 


\section{Appendix 1 \\ MODIFIED NURSE-ASSESSED PATIENT COMFORT SCORE (NAPCOMS)}

Trainee? Yes/no

Scope used: Adult/ Pediatric, other

\begin{tabular}{|c|c|c|c|}
\hline \multicolumn{4}{|l|}{ Patient } \\
\hline \multicolumn{3}{|l|}{ 1) Age } & \\
\hline 2) Gender & Male & Female & \\
\hline 3) Previous colonoscopy & Yes & No & If yes to (4) or (5), please lis \\
\hline 4) Previous bowel, bladder, or pelvic surgery & Yes & No & \\
\hline
\end{tabular}

\section{NAPCOMS}

\begin{tabular}{|c|c|c|c|c|c|}
\hline Domain & Item & 0 & 1 & 2 & 3 \\
\hline \multirow[t]{3}{*}{ Pain } & 1) Intensity & None or minimal & Mild & Moderate & Severe \\
\hline & 2) Frequency & None & Few (1 - 2 episodes) & $\begin{array}{l}\text { Several times } \\
\text { (3-4 episodes) }\end{array}$ & Frequent (>4 episodes) \\
\hline & 3) Duration & None & $\begin{array}{l}\text { Short duration (episode } \\
<30 \text { seconds) }\end{array}$ & $\begin{array}{l}\text { Moderate duration } \\
\text { (30 seconds }-1 \text { minute) }\end{array}$ & $\begin{array}{l}\text { Long duration (episodes } \\
\text { last } \geq 1 \text { minute) }\end{array}$ \\
\hline Sedation & $\begin{array}{l}\text { Level of con- } \\
\text { sciousness }\end{array}$ & Alert & $\begin{array}{l}\text { Sleepy but initiates } \\
\text { conversation. }\end{array}$ & $\begin{array}{l}\text { Responds only when } \\
\text { asked or stimulated. }\end{array}$ & $\begin{array}{l}\text { Unresponsive or only re- } \\
\text { sponds with pronounced } \\
\text { stimulation. }\end{array}$ \\
\hline Global & Tolerability & $\begin{array}{l}\text { Very well } \\
\text { tolerated. }\end{array}$ & Reasonably well tolerated. & Just tolerated. & Poorly tolerated. \\
\hline $\begin{array}{l}\text { Complica- } \\
\text { tions }\end{array}$ & $\begin{array}{l}\text { Vasovagal } \\
\text { Event }\end{array}$ & HTN & Tachycardia & Other (please list): & \\
\hline
\end{tabular}

\section{PROCEDURAL DOCUMENTATION}

\begin{tabular}{|l|l|l|l|l|l|l|}
\hline Sedative & Midazolam $(\mathrm{mg})$ & Fentanyl $(\mathrm{mcg})$ & Buscopan (mg) \\
\hline Duration (mins): & $\begin{array}{l}\text { Number of Position } \\
\text { Changes: }\end{array}$ & Abdominal Pressure Applied & NES \\
\hline
\end{tabular}

